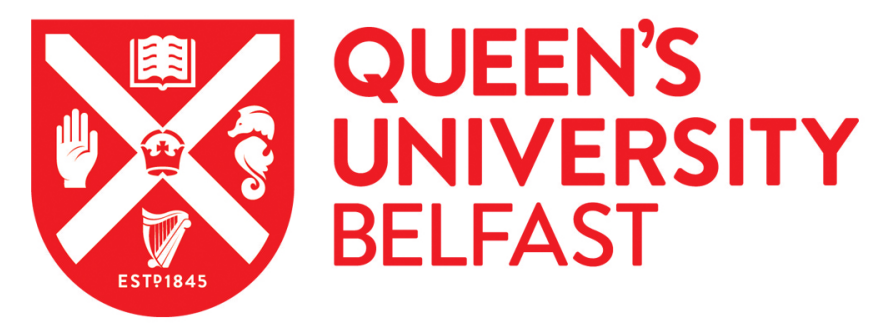

\title{
Patients' attitudes to co-payments for general practitioner services: do they reflect the prevailing system
}

O'Reilly, D., O'Neill, C., O'Dowd, T., Galway, K., Gilliland, A., Kelly, A., Murphy, A., Shryane, E., Steele, K., \& Bury, G. (2007). Patients' attitudes to co-payments for general practitioner services: do they reflect the prevailing system. Journal of Health Services Research \& Policy, 12, 197-201.

Published in:

Journal of Health Services Research \& Policy

Document Version:

Publisher's PDF, also known as Version of record

Queen's University Belfast - Research Portal:

Link to publication record in Queen's University Belfast Research Portal

\section{General rights}

Copyright for the publications made accessible via the Queen's University Belfast Research Portal is retained by the author(s) and / or other copyright owners and it is a condition of accessing these publications that users recognise and abide by the legal requirements associated with these rights.

Take down policy

The Research Portal is Queen's institutional repository that provides access to Queen's research output. Every effort has been made to ensure that content in the Research Portal does not infringe any person's rights, or applicable UK laws. If you discover content in the Research Portal that you believe breaches copyright or violates any law, please contact openaccess@qub.ac.uk. 


\title{
Patients' attitudes to co-payments for general practitioner services: do they reflect the prevailing system?
}

\author{
Dermot O'Reilly, Ciaran O'Neill'1, Tom O'Dowd ${ }^{2}$, Karen Galway, Andrew Gilliland ${ }^{3}$, Alan Kelly², \\ Andrew Murphy ${ }^{4}$, Ethna Shryane ${ }^{4}$, Keith Steele ${ }^{3}$, Gerry Bury ${ }^{5}$ \\ Department of Epidemiology and Public Health, Queen's University Belfast, UK; ${ }^{1}$ School of Economics and Politics, University of Ulster, \\ Belfast, UK; ${ }^{2}$ Department of Public Health and Primary Care, Trinity College, Dublin, Ireland; ${ }^{3}$ Department of General Practice, Queen's \\ University Belfast, Belfast, UK; ${ }^{4}$ Department of General Practice, National University of Ireland, Galway, Ireland; ${ }^{5}$ Coombe Healthcare \\ Centre, University College Dublin, Dublin, Ireland
}

Objectives: Most Organisation for Economic Co-operation and Development (OEGD) countries have introduced cost-sharing. This study compares the views of patients who are used to a service that is free at the point of delivery with those who are used to a system where $70 \%$ of patients pay for consultations.

Methods: Secondary analysis of survey data from a random sample of 11,870 patients in Northern Ireland and the Republic of Ireland.

Results: A $52 \%$ response rate was achieved, though respondents were representative of the two populations. Attitudes generally reflected the national status quo with little support for co-payments where there was currently no charging, but broad support where charging was established. Charging for missed appointments would be supported where there were delays in getting an appointment.

Conclusions: More research is needed to understand what underlies support for, or opposition to, charges. However, it is apparent that patients' opinions need to be considered when formulating health care policy.

Journal of Health Services Research E Policy Vol 12 No 4, 2007: 197-201

(C) The Royal Society of Medicine Press Ltd 2007

\section{Introduction}

Most countries strive to control rising health care costs by focusing on supply side factors, such as primary care gatekeeping or utilization review, ${ }^{1,2}$ or on demand side factors $^{3-6}$ such as cost-sharing including co-payments and deductibles. ${ }^{7}$ Demand side measures such as costsharing are intended to address the tendency for individuals to 'over-consume' when direct costs do not reflect full costs. ${ }^{8}$ Many of the countries in the Organisation for Economic Co-operation and Development (OECD) have considered some form of costsharing, principally as a way of making consumers more cost-conscious and therefore more discerning about their demand for health care. ${ }^{9}$

Dermot O'Reilly MD, Senior Lecturer, Clinical and Population Sciences, Karen Galway PhD, Research Fellow, Department of Epidemiology and Public Health, Andrew Gilliland MD, Senior Lecturer, Keith Steele MD, Professor, Department of General Practice, Queen's University Belfast, Mulhouse Building, Royal Victoria Hospital, Grosvenor Road, Belfast BT5 7AW, UK; Giaran O'Neill PhD, Professor, School of Economics and Politics, University of Ulster, Belfast, UK; Tom O'Dowd MD, Professor, Alan Kelly PhD, Statistician, Department of Public Health and Primary Care, Trinity College, Dublin, Ireland; Andrew Murphy MD, Professor, Ethna Shryane BSc MSc, Research Associate, Department of General Practice, National University of Ireland, Galway, Ireland; Gerry Bury MD, Professor of General Practice, Coombe Healthcare Centre, University College Dublin, Ireland.

Correspondence to: d.oreilly@qub.ac.uk
Cost-sharing is not unproblematic. ${ }^{10-14}$ While even relatively small charges can be very effective at reducing demand for health services, ${ }^{4,15}$ they affect both appropriate or highly effective care and inappropriate or rarely effective care. ${ }^{16}$ They also disproportionately affect the poorest and those with the worst health, ${ }^{14}$ changing access to health care from one based primarily on need towards one based on the ability to pay. These effects, as well as the greater incentive for providers to exploit their position where there are charges, ${ }^{17}$ have fuelled debate regarding their merits and led some countries to operate exemptions from payments for the most vulnerable. ${ }^{10-13}$

Little is known about the attitude of users to the principle of out-of-pocket charges. It is probably assumed that users will favour a system where services are provided free at the point of delivery, though it could also be argued that considerable support exists for charges, given their effect on consumption and facilitation of faster access. ${ }^{18}$ The aim of this paper is to compare the views of users on charging for general practitioner (GP) services, which is timely considering the recent debates about charging in the UK and Republic of Ireland (RoI). ${ }^{19-21}$ Given the differences in the incidence of charges, the comparison of attitudes between the two countries may offer an insight into the role that familiarity with a system has upon attitudes. 
The RoI health care system is a mixture of public and private schemes. Before 2001, eligibility for services was dependent on the level of household income with those below a defined income (after adjustment for age and number of dependants) being entitled to health care services free at the point of contact. In 2001, this was extended to include all patients aged 70 years and over, irrespective of income. General Medical Services (GMS) eligible patients now comprise about $30 \%$ of the population. All non-GMS patients pay a flat rate of approximately $€ 35-55$ (median US $\$ 65$ ) to see their GP. In Northern Ireland (NI), like the rest of the UK, a universal health care system, free at the point of delivery, operates. A recent paper has demonstrated that more than one in four of those non-GMS (paying) patients in RoI have been deterred from seeing their GP due to the cost and that the deterrent effects are most pronounced among the poor and the sick. ${ }^{21}$

\section{Methods}

The data for this analysis were collected as part of a large survey of patients in selected practices in RoI and NI. ${ }^{21}$ Twenty practices were selected in RoI to provide a nationally representative mix of practices according to location (rural, small town and city) and practice size (one of three groups based on whole-time-equivalent GP principals). ${ }^{22} \mathrm{~A}$ random selection of 20 practices in NI was then drawn to match those in RoI and a random selection of 625 patients drawn from practice lists using computer generated random numbers, with no more than two people selected from any household. Parents/guardians were asked to complete questionnaires on behalf of patients under 16 years. The survey was conducted during October and November 2003.

In addition to the usual demographic variables, an array of socioeconomic data was collected including car ownership (categorized as no car, one or more cars, two or more cars); tenure (dichotomized into renting and non-renting); and academic attainment (three levels of educational attainment; primary school only, secondary level, tertiary level). Gross annual household income was also measured and adjusted for the number and type of dependants in the household. ${ }^{23}$ Health measures included limiting long-term illness, general health over the preceding year and a two-question instrument for detecting patients at high risk of depression in a primary setting. ${ }^{24}$ A question identical to one included in the Commonwealth Fund International Survey of inequalities in health care ${ }^{25}$ asked whether patients had had a health problem in the previous year, but had been deterred from attending their GP due to the cost.

Patients were asked three questions regarding consultation charges; these related to consultations with the GP either at the surgery, at home during working hours, or out of hours such as evenings or weekends. A separate question was asked about charging for missed appointments.
The $\chi^{2}$ test was used to test for differences in the proportion of users across the various demographic and socioeconomic strata. Logistic regression analysis was undertaken to explore the independent effects of the various factors on user attitudes. Analysis was carried out in STATA with adjustment for the clustering of users within practices (using robust estimation).

\section{Results}

Completed responses were obtained from 11,870 respondents giving an overall response rate of $52 \%$. Attitudes to charging in different circumstances and between the two countries are reported in Table 1. The overwhelming majority of patients in NI (where no charges currently exist) was opposed to charging for any GP consultations, either at the surgery or at home. The majority of patients in RoI was in favour of charging with an overwhelming majority of those who currently pay being in favour of such charges. A greater proportion in both countries supported charging for home visits, especially those that occur out of office hours, perhaps in recognition of the additional work involved. Over $70 \%$ of NI users thought it was reasonable to charge for missed appointments compared with only $30 \%$ in RoI.

In RoI, support for charging was strongly related to income (Figure 1), though even in the poorest septile approximately $50 \%$ of the population was in favour of consultation charges. In contrast, in NI, the lack of enthusiasm for charging was fairly consistent across the income distribution. In RoI, those who had previously been deterred by the consultation charge were less likely than those who had not been deterred to indicate that it was reasonable to have to pay to see the GP, either at the surgery or for a home visit during working hours (Table 2). However, even among this group, the majority was in favour of consultation charges. Having been affected by the consultation charge in the previous year did not change the proportions in favour of charges for out of hours home visits or missed appointments. Very few people in NI had been affected by the cost of going to the $\mathrm{GP}^{21}$ and this made little difference to their views on charging policy.

Table 1 Proportions of respondents who think it is reasonable to charge for various GP services

\begin{tabular}{lcll}
\hline & \multicolumn{3}{l}{ Rol (\%) } \\
\cline { 3 - 4 } Suggested charge & NI (\%) & GMS & Non-GMS \\
\hline To see GP at surgery & 7.5 & 53.3 & 74.9 \\
For home visits by GP & & & \\
$\begin{array}{l}\text { During working hours } \\
\text { At weekends and evenings }\end{array}$ & 18.2 & 67.5 & 79.5 \\
For missed appointments & 71.0 & 33.8 & 29.5 \\
\hline
\end{tabular}

Fisher's exact test for all differences between $\mathrm{NI}$ and the Rol are at the $<0.001$ level; all differences between GMS and non-GMS patients are significant at the $<0.001$ level except for 'missed appointments' which was significant at the 0.012 level 
Three sets of logistic regression analyses were undertaken to characterize patients who thought it reasonable to charge for different types of GP service. This was only undertaken for RoI as the proportions in favour of charging were very low in NI. The results (Table 3) demonstrate that support for a consultation charge increased with age, with those patients aged over 70 years being three times more likely than those under 20 years to agree that it was reasonable to pay to see the GP at the surgery. There was no difference between the sexes and, once adjustment had been made for socioeconomic status, there was no association with marital status. Patients who were from more affluent households were more supportive of charging than those who were less well off. Those without a medical card (the paying patients) were more than twice as likely to support consultation charging. Not surprisingly, those who had been deterred from seeing the GP in the previous year because of cost were much less enthusiastic about a charging policy. Once differences in age and socioeconomic status had been controlled for, there was no independent association between health status and willingness to accept a consultation charge. Essentially the same models were produced for consultation charges for home visits either during working hours or out of hours; the principal difference was the absence of a significant relationship with age in either model.

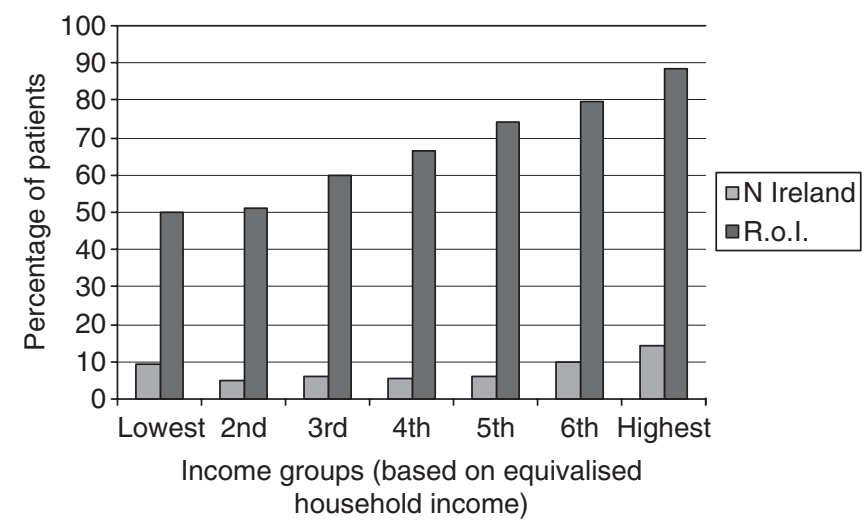

Figure 1 Variations across the income spectrum in the proportion of patients in the Rol and NI who think it is reasonable to have to pay to see the GP in the surgery

\section{Discussion}

Approximately $70 \%$ of patients in RoI have to pay to see the GP, with exemptions for the poorest and those aged over 70 years. GPs do not have a prominent gatekeeper role and patients expect, and generally receive, rapid access to both GP and hospital services. By contrast, no charges are levied for GP consultations in NI, but GPs have a more significant gatekeeper role for access to secondary care services and, as in the rest of the UK, there are accusations of 'rationing by waiting list'.

The views of users in the two countries towards charges for GP services both reflected and supported the differences in the two health care systems. In NI, where services are free at the point of delivery, there was little support for the introduction of consultation charges; in the RoI, where consultation charges are the reality for the majority of the population, consultation charges were broadly supported. In NI, where appointment systems to see the GP are more common and waiting times are a concern, patients were much more willing, than those in RoI, to consider the introduction of charges for missed appointments.

Neither set of results is surprising; one would not expect opposition to charging to be strong among those who do not pay for services in the RoI, given that they enjoy relatively rapid access and do not incur a direct cost. That support is evident among those who do pay likely reflects the relatively high value attached to time that would otherwise be spent waiting for an appointment compared with the level of the charge, as well as, perhaps, resignation born from familiarity with the existence of charges. The degree of opposition to charges for primary care in NI mirrors that found by Park et al. ${ }^{26}$ in Britain who suggest that this cannot be attributed to ignorance of the level and mechanics of a charging system. In Park et al.'s study, opposition remained unaffected by deliberative polling (provision of additional information), suggesting that primary care delivered free at the point of use is a cherished feature of the UK health care system. ${ }^{26}$ Interestingly, attitudes of users in the UK are shared by GPs. The 2001 survey of GPs conducted by the British Medical Association found that $67 \%$ of GPs in NI opposed the introduction of charges for 'all patients'. ${ }^{27}$

Table 2 Proportion of patients in the Rol and NI who feel it is reasonable to pay for GP services according to whether they had been affected by costs in the previous year, i.e. had a medical problem but did not see the GP because of cost

\begin{tabular}{llllll}
\hline & \multicolumn{2}{l}{$\mathbf{N}$} & & \multicolumn{2}{l}{ Rol } \\
\cline { 2 - 3 } Suggested charge & Not affected by cost (\%) & Affected by cost (\%) & Not affected by cost (\%) & Affected by cost (\%) \\
\hline To see GP at surgery & 7.6 & 3.5 & $69.5^{* *}$ & 58.2 \\
For home visits by GP & & & & 66.9 \\
During working hours & 8.6 & 5.8 & $72.0^{*}$ & 81.9 \\
At weekends and evenings & 18.3 & 13.3 & 81.1 & 30.8 \\
For missed appointments & 71.0 & 71.7 & 31.0 & \\
\hline
\end{tabular}

${ }^{*}<0.01 ;{ }^{* *}<0.001$ 
Table 3 Results of logistic regression to determine which types of patients in the Rol felt it was reasonable to charge for a consultation with the GP at the surgery

\begin{tabular}{|c|c|c|c|}
\hline & \multirow[b]{2}{*}{ Consultation in surgery } & \multicolumn{2}{|l|}{ Home visits } \\
\hline & & Office hours & Out of hours \\
\hline \multicolumn{4}{|l|}{ Age (years) } \\
\hline $0-19$ & 1.00 & 1.00 & 1.00 \\
\hline $20-44$ & $1.94(1.31,2.87)^{\star * *}$ & $0.99(0.66,1.49)$ & $0.82(0.50,1.33)$ \\
\hline $45-69$ & $2.79(1.89,4.12)^{\star * \star}$ & $1.30(0.87,1.95)$ & $0.88(0.54,1.42)$ \\
\hline $70+$ & $3.08(1.98,4.80)^{\star * *}$ & $1.38(0.88,2.18)$ & $0.93(0.55,1.59)$ \\
\hline \multicolumn{4}{|l|}{ Sex } \\
\hline Men & 1.00 & 1.00 & 1.00 \\
\hline Women & $1.03(0.87,1.21)$ & $1.03(0.87,1.21)$ & $1.06(0.88,1.29)$ \\
\hline \multicolumn{4}{|l|}{ Tenure } \\
\hline Owner & 1.00 & 1.00 & 1.00 \\
\hline Renting & $0.62(0.50,0.76)^{* * *}$ & $0.64(0.51,0.79)^{\star * *}$ & $0.81(0.63,1.04)$ \\
\hline \multicolumn{4}{|l|}{ Cars in household } \\
\hline None & 1.00 & 1.00 & 1.00 \\
\hline One & $1.39(1.10,1.75)^{\star}$ & $1.31(1.04,1.64)^{*}$ & $1.37(1.06,1.76)^{\star}$ \\
\hline Two or more & $1.46(1.12,1.90)^{\star *}$ & $1.51(1.16,1.96)^{\star \star}$ & $1.67(1.24,2.26)^{* * *}$ \\
\hline \multicolumn{4}{|l|}{ Educational level } \\
\hline Primary & 1.00 & 1.00 & 1.00 \\
\hline Secondary & $1.26(1.03,1.54)^{*}$ & $1.51(1.30,1.93)^{\star \star \star}$ & $1.35(1.07,1.69)^{\star *}$ \\
\hline Tertiary & $1.24(0.96,1.60)$ & $1.34(1.05,1.71)^{*}$ & $1.15(0.86,1.54)$ \\
\hline \multicolumn{4}{|l|}{ Income category } \\
\hline Lowest & 1.00 & 1.00 & 1.00 \\
\hline Second & $1.05(0.80,1.38)$ & $1.05(0.80,1.38)$ & $1.02(0.77,1.36)$ \\
\hline Third & $1.11(0.85,1.44)$ & $1.03(0.79,1.34)$ & $1.37(1.02,1.83)^{*}$ \\
\hline Fourth & $1.70(1.21,2.38)^{\star *}$ & $1.64(1.17,2.30)^{\star \star}$ & $1.86(1.26,2.75)^{\star *}$ \\
\hline Fifth & $1.87(1.35,2.58)^{\star * \star}$ & $1.72(1.25,2.36)^{\star \star \star}$ & $2.16(1.48,3.14)^{\star \star \star}$ \\
\hline Sixth & $1.80(1.26,2.58)^{\star * *}$ & $1.82(1.27,2.60)^{* *}$ & $2.43(1.57,3.76)^{\star * *}$ \\
\hline Highest & $2.40(1.55,3.71)^{\star \star *}$ & $2.13(1.39,3.27)^{\star * *}$ & $6.36(3.15,12.8)^{\star \star *}$ \\
\hline \multicolumn{4}{|l|}{ GMS status } \\
\hline Free care & 1.00 & 1.00 & 1.00 \\
\hline Charge imposed & $2.59(2.05,3.28)^{\star * *}$ & $2.30(1.82,2.89)^{\star * *}$ & $2.21(1.69,2.89)^{\star * *}$ \\
\hline \multicolumn{4}{|l|}{ Cost avoidance ${ }^{\dagger}$} \\
\hline No & 1.00 & 1.00 & 1.00 \\
\hline Yes & $0.37(0.30,0.46)^{* * *}$ & $0.51(0.41,0.63)^{\star * *}$ & $0.68(0.52,0.89)^{* *}$ \\
\hline
\end{tabular}

${ }^{*}<0.05 ;{ }^{* *}<0.01 ;{ }^{* * *}<0.001$

†Patients with a health problem who had not attended their GP in the last year due to cost

It is likely that the consultation charges in RoI lower demand for GP services and shorten waiting time for an appointment, obviating the need to introduce a charge to address this issue. By contrast in the UK system, where demand is strictly rationed by waiting, waiting time is likely to be relatively longer and the opportunity costs associated with missed appointments for all service users are likely to be relatively higher. That individuals may be more receptive to the use of charges as a means of encouraging scheduled appointments to be kept is thus expected. The views of the NI public seem to accord with those of the GPs in the UK generally, as $67 \%$ of GPs questioned supported the introduction of charges for missed appointments, ${ }^{28}$ which they thought increased waiting times.

The study does, however, throw up some surprises. A majority of patients in RoI, who had in the previous year been deterred by the consultation charge from seeing a GP when they had had a medical problem, still favoured the existence of a consultation charge. Even allowing for the possibility that the missed visits related to minor ailments, one would have expected such patients to favour an abolition of charges. It is possible that individuals are willing to sacrifice visits for minor ailments in return for faster access on other occasions.

Within Ireland, the results are consistent with expectations. As incomes increase, so the relative cost of a charge will diminish. If faster access is permitted by charges, as the relative cost of attaining this falls, so one would anticipate opposition to charging to diminish. This is indeed the case as seen in the odds ratios related to income in Table 3. These results are broadly mirrored in respect of home visits. Similarly, relative to those who had missed an appointment due to cost, the greater support for charges among those who had not is as one would expect.

The response rate to the survey was in line with large population-based studies in RoI. Analysis indicated that respondents and the sample were reasonably matched and re-weighting the data to represent the national age and sex distributions produced no significant differences in any of the models presented. 
An acknowledged limitation of the question design is that those in favour of charging do not necessarily mean that this should apply to them. Presumably, the GMS patients and those towards the lower end of the RoI socioeconomic scale were in favour of the more affluent patients continuing to pay for service. Due to limitations in survey space, the study was not able to explore patients' preferred funding options such as increased taxation versus consultation charges, or the patient value systems that produced these views on charging. Further qualitative research could explore these issues or gauge support for amendments to the system such as extending the numbers to whom exemptions are offered or the level of charges levied.

\section{Conclusions}

In respect of charges for GP services, the study indicates broad support for the current positions of the two health care systems on the island of Ireland among the populations they serve. Variations in support by socioeconomic group within RoI are in line with expectations and likely reflect the relative cost of charges to different groups. In NI, support does exist for the use of charges for missed appointments, a position echoing that of service providers. Whether such a system would be practical, given the probability that it would have to incorporate a system of exemptions, is debatable. There is minimal public support for charging beyond this in NI, a finding that again echoes that of NI GPs. ${ }^{27}$ However, what underlies support for or opposition to charges warrants further investigation.

\section{References}

1 Delnoij D, Van Merode G, Paulus A, Groenewegen P. Does general practitioner gatekeeping curb health care expenditure? J Health Serv Res Policy 2000;5:22-6

2 Ginsburg P. Controlling health care costs. N Engl J Med 2005;351:1591-3

3 Khandker RK, Manning WG, Ahmed T. Utilization review savings at the micro level. Med Care 1992;30:1043-52

4 Abel-Smith B. Cost containment and new priorities in the European community. Milbank $Q$ 1992;70:393-416

5 Marquez P. Containing health costs in the Americas. Health Policy Plan 1990;5:299-315

6 Ess SM, Schneeweiss S, Szucs TD. European healthcare policies for controlling drug expenditure. Pharmacoeconomics 2003;21:89-103

7 Lee JS, Tollen L. How low can you go? The impact of reduced benefits and increased cost sharing. Health Aff (Millwood) 2002;W229-41; Suppl Web Exclusives

8 Pauly M. The economics of moral hazard: comment. $A m$ Econ Rev 1968;58:531-7
9 Ros C, Groenewegen P, Delnoij D. All rights reserved, or can we just copy? Cost sharing arrangements and characteristics of health care systems. Health Policy 2000;52:1-13

10 Scott KM, Marwick JC, Crampton PR. Utilization of general practitioner services in New Zealand and its relationship with income, ethnicity and government subsidy. Health Serv Manage Res 2003;16:45-55

11 Soumerai SB, Avorn J, Ross-Degnan D, Gortmaker S. Payment restrictions for prescription drugs under Medicaid: effect on therapy, cost, and equity. $N$ Engl $J$ Med 1987;317:550-6

12 Soumerai SB, Ross-Degnan D, Avorn J, McLaughlin TJ, Choodnovskiy I. Effects of Medicaid drug-payment limits on admission to hospitals and nursing homes. $N$ Engl J Med 1991;325:1072-7

13 Soumerai SB, McLaughlin TJ, Ross-Degnan D, Casteris CS, Bollini P. Effects of limiting Medicaid drug-reimbursement benefits on the use of psychotropic agents and acute mental health services by patients with schizophrenia. $N$ Engl J Med 1994;331:650-5

14 Newhouse JP, The Insurance Experiment Group. Free for All? Lessons from the RAND Health Insurance Experiment. Cambridge, MA: Harvard University Press, 1993

15 Cherkin DC, Grothaus L, Wagner EH. The effect of office visit copayments on preventive care services in an HMO. Inquiry 1990;27:24-38

16 Siu AL, Sonnenberg FA, Manning WG. Inappropriate use of hospitals in a randomised trial of health insurance plan. $N$ Engl J Med 1986;315:1259-66

17 McGuire A, Fenn P, Mayhew K, eds. Providing Health Care: The Economics of Alternative Systems of Finance and Delivery. Oxford: Oxford University Press, 1991

18 O'Connell S. The financial cost to patients of visiting a GP in Ireland: a cross-sectional survey. Ir J Med Sci 2001; 170:45-8

19 Reggler J. User fees would both yield money and encourage more responsible use of NHS. BMJ 1998;316:70

20 Ward L. Patients ready to pay to see GP says Tory leader. Guardian 17 December 2001

21 Galway KJ, Murphy RW, O'Reilly D, et al. Perceived and reported access to the general practitioner: an international comparison of universal access and mixed private/public systems. Irish Medical Journal 2007;10:494-8

22 Gabhainn SN, Murphy AW, Kelleher CC. A national general practice census: characteristics of rural general practices. Fam Pract 2001;18:622-6

23 Davies H, Joshi H, Clarke L. Is it cash the deprived are short of? I R Stat Soc 1997;160:107-26

24 Whooley MA, Avins AL, Miranda J, Browner WB. Casefinding instruments for depression: two questions are as good as many. J Gen Intern Med 1997;12:439-45

25 Blendon R, Schoen C, DesRoches C, Osborn R, Scoles K, Zapert K. Inequalities in health care: a five-country survey. Health Aff (Millwood) 2002;21:182-91

26 Park A, Jowell R, McPherson S. The future of the National Health Service: results from a deliberative poll. See http:// cdd.stanford.edu/research/papers/2000/report_kings_fund.pdf (accessed November 2004)

27 BMA. See http://www.bma.org.uk/ap.nsf/Content/GPC+-+ National+Survey+of+GP+opinion + 2001

28 Doctor patient partnership. See http://www.dpp.org.uk/ downloads/UK2004.pdf 